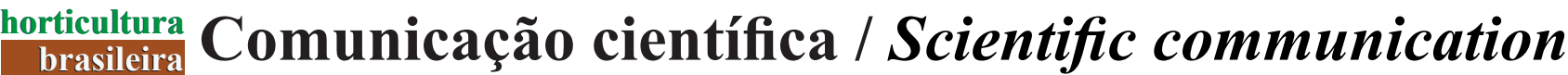

TORRES, SB; BALBINO, DAD; SANTOS, WGN; NOGUEIRA, NW; FREITAS, RMO; LEITE, MS. 2016. Avaliação do vigor de sementes de rúcula pela atividade respiratória. Horticultura Brasileira 34: 561-564. DOI - http://dx.doi.org/10.1590/S0102-053620160416

\section{Avaliação do vigor de sementes de rúcula pela atividade respiratória}

\author{
Salvador B Torres ${ }^{1}$; Deyse AD Balbino; Wigna GN Santos ${ }^{1}$; Narjara W Nogueira ${ }^{1}$; Rômulo MO Freitas ${ }^{2}$; \\ Moadir S Leite ${ }^{1}$ \\ ${ }^{1}$ Universidade Federal Rural do Semi-Árido (UFERSA), Mossoró-RN, Brasil; sbtorres@ufersa.edu.br; nane_deyse@hotmail.com; \\ wignagabi@hotmail.com; narjarawalessa@yahoo.com.br; moadir@outlook.com; ${ }^{2}$ Instituto Federal de Educação, Ciência e Tecnologia \\ Baiano (IFBaiano), Valença-BA, Brasil; romulomagno_23@hotmail.com
}

\section{RESUMO}

A atividade respiratória pelo método Pettenkofer é uma possível alternativa aos testes tradicionais para a determinação do vigor de lotes de sementes. O objetivo deste trabalho foi verificar a eficiência do método de Pettenkofer na determinação da atividade respiratória, para diferenciar o vigor de lotes de sementes de rúcula, cultivares Cultivada e Folha Larga. O delineamento experimental foi inteiramente casualizado, com quatro repetições, sendo as médias comparadas pelo teste de Tukey a 5\% de probabilidade. Os dados de germinação e vigor (atividade respiratória) foram submetidos à análise de correlação. Além da atividade respiratória foram realizados os testes de germinação, emergência de plântulas e lixiviação de potássio. Os resultados dos diferentes testes realizados permitiram a classificação dos lotes em diferentes níveis de qualidade fisiológica, sendo a determinação da atividade respiratória pelo método de Pettenkofer eficiente, rápida e útil, como alternativa na diferenciação do vigor de lotes de sementes de rúcula.

\begin{abstract}
Assessment of rocket seed vigor through respiration activity

Respiration activity estimated by the Pettenkofer method is a possible alternative to traditional tests for determining vigor of seed lots. In this sense, this work aimed to verify the Pettenkofer method efficiency for estimating respiratory activity, in order to differentiate vigor of rocket seed lots, cultivars Cultivada and Folha Larga. Experimental design was completely randomized blocks with four replications and means were compared by Tukey, $5 \%$. Germination and vigor data (respiratory activity) were subjected to correlation analysis. Besides respiratory activity we carried out tests of germination, seedling emergence and potassium leaching. Results allowed classifying lots according to their physiological quality. Determining respiratory activity by the Pettenkofer method was considered efficient, fast and useful to differentiate rocket seed vigor.
\end{abstract}

Keywords: Eruca sativa, respiration, physiological quality.

Palavras-chave: Eruca sativa, respiração, qualidade fisiológica.

(Recebido para publicação em 22 de maio de 2015; aceito em 16 de abril de 2016)

(Received on May 22, 2015; accepted on April 16, 2016)

$\mathrm{D}$ esde meados da década de 1990 a rúcula vem conquistando espaço crescente no mercado brasileiro de hortaliças (Alves \& Sá, 2010). O aumento no consumo pode ser explicado pela sua composição nutricional, apresentando altos teores de potássio, enxofre, ferro e vitaminas, além de seu sabor picante e agradável (Trani \& Passos, 1998). Pertencente à família Brassicaceae, essa espécie tem sua produção, em quase sua totalidade, representada pelas cultivares 'Cultivada' e 'Folha Larga' (Silva et al., 2009). Custos com sementes e mão de obra podem onerar a sua produção; portanto, pesquisas relacionadas com a qualidade das sementes, a fim de reduzir os custos de produção são necessárias. Sementes com alto potencial fisiológico, normalmente, apresentam germinação rápida e uniforme em condições de campo, originando plantas com características desejáveis pelo comércio (Pêgo et al., 2011).

O teste de germinação é um dos mais utilizados para a determinação da qualidade fisiológica de lotes de sementes; no entanto, segundo Coimbra et al. (2009), este teste isoladamente não é eficiente, sendo necessária a complementação com resultados da avaliação do vigor. Esta tem sido cada vez mais utilizada pela indústria de sementes visando a determinação do potencial fisiológico de sementes (Alves \& Sá, 2009).

Os testes de vigor permitem estimar o potencial fisiológico das sementes, com a identificação de diferenças significativas entre lotes, geralmente, não detectadas pelo teste de germinação
(ISTA, 2012). Além da determinação do potencial para emergência rápida e uniformidade de plântulas, outros fatores devem ser incluídos na realização desses testes como a rapidez, objetividade, simplicidade e baixo custo (Marcos-Filho, 2015).

Diversos testes de vigor têm sido desenvolvidos procurando avaliar e relacionar, com precisão, o comportamento de lotes de sementes em laboratório. Dentre estes, o de respiração proporcionou resultados promissores na diferenciação do vigor de lotes de sementes de soja e arroz usando o aparelho de Pettenkofer (Mendes et al., 2009).

A respiração é uma das primeiras atividades metabólicas das sementes logo após a reidratação: de quase nula, atinge valores elevados em pouco tempo, de- 
pendendo da espécie (Pinã-Rodrigues et al., 2004). Na respiração, a atividade de enzimas e de organelas e a síntese de proteínas são eventos fundamentais para o desenvolvimento normal do processo de germinação e preparo para o crescimento subsequente do embrião (Pereira, 2012).

A avaliação da atividade respiratória em laboratório, utilizando o método Pettenkofer, foi considerada por Mendes et al. (2009) uma alternativa aos testes tradicionais para a determinação do vigor de um lote de sementes. O uso desse método mostrou-se eficiente para avaliar o vigor de sementes de soja (Mendes et al., 2009; Dode et al., 2013), girassol (Dode et al., 2012) e feijão-miúdo (Aumonde et al., 2012). No entanto, as pesquisas utilizando esse método para avaliar lotes de sementes de hortaliças são escassas, estando disponíveis informações sobre sua aplicação apenas em sementes de pimenta e pimentão (Pereira, 2012) e melancia (Oliveira et al., 2015).

Dessa forma, este trabalho foi desenvolvido com o objetivo de verificar a eficiência do método de Pettenkofer na determinação da atividade respiratória, para diferenciar o vigor de lotes de sementes de rúcula.

\section{MATERIAL E MÉTODOS}

O experimento foi conduzido no Laboratório de Análise de Sementes e em casa de vegetação do Departamento de Ciências Vegetais da Universidade Federal Rural do Semi-Árido (UFERSA), em Mossoró-RN, no período de agosto a novembro de 2013. As sementes de rúcula, cultivares Cultivada e Folha Larga, cada uma representada por cinco lotes, foram obtidas junto a empresas nacionais produtoras de sementes, produzidas no ano agrícola 2012/2013. O delineamento experimental utilizado foi inteiramente casualizado, com quatro repetições. Durante todo o período experimental, as sementes permaneceram embaladas em sacos de papel Kraft e armazenadas em câmara fria e seca a $10^{\circ} \mathrm{C}$ e $50 \%$ de umidade relativa do ar. As sementes foram submetidas aos seguintes testes e determinações.
Teor de água - avaliação conduzida pelo método da estufa, a $105 \pm 3^{\circ} \mathrm{C}$, por 24 horas, utilizando-se duas subamostras para cada lote, sendo os resultados expressos em porcentagem, base úmida (Brasil, 2009).

Germinação - conduzido com quatro repetições de 50 sementes por lote, em caixas plásticas transparentes (11 x 11 x $3,5 \mathrm{~cm}$ ) distribuídas sobre duas folhas de papel mata-borrão umedecidas com água destilada, em quantidade correspondente a 2,5 vezes a massa seca do substrato e colocadas em germinador, a $20^{\circ} \mathrm{C}$, na ausência de luz. As contagens foram efetuadas aos quatro (primeira contagem) e sete dias após a semeadura, segundo os critérios estabelecidos pelas Regras para Análise de Sementes (Brasil, 2009).

Emergência de plântulas - realizado em casa de vegetação com quatro repetições de 50 sementes por lote. A semeadura foi realizada em bandejas de poliestireno expandido com 128 células, preenchidas com o substrato comercial Tropstrato $^{\circledR}$. Realizou-se a contagem diária do número de plântulas emersas até o décimo dia após a semeadura; esta data foi considerada como a correspondente à estabilização da emergência de plântulas. Calculou-se o índice de velocidade (Maguire, 1962) e a porcentagem de emergência de plântulas.

Lixiviação de potássio - utilizou-se a metodologia descrita por Alves \& Sá (2010). Quatro repetições de 50 sementes de cada lote foram pesadas $(0,1 \mathrm{mg})$, colocadas em copos de plástico contendo $50 \mathrm{~mL}$ de água destilada e mantidas em incubadora tipo Biochemical Oxygen Demand (B.O.D.) por duas horas a $30^{\circ} \mathrm{C}$, sendo as leituras realizadas com fotômetro de chama ANALYSER-910. Para o cálculo da lixiviação de potássio, considerou-se a leitura obtida no fotômetro de chama, o volume utilizado de água destilada $(\mathrm{mL})$ e a massa da amostra (g); os resultados foram expressos em $\mu \mathrm{g}$ de $\mathrm{K} / \mathrm{g}$ de semente (ppm de potássio).

Atividade respiratória - procurou-se adaptar a metodologia descrita por Mendes et al. (2009) para sementes de soja, utilizando-se quatro repetições. Cada repetição foi constituída de dois gramas de sementes de rúcula por lote. Para isso, empregou-se o aparelho de
Pettenkofer, constituído por quatro frascos lavadores de gases, dos quais dois possuíam hidróxido de sódio a $25 \%$, que tinha como função a retenção do $\mathrm{CO}_{2}$ do ar ambiente; um frasco destinado ao armazenamento das sementes em estudo, isento de $\mathrm{CO}_{2}$ do ar ambiente; e, o outro, contendo hidróxido de bário $\left\{\mathrm{Ba}(\mathrm{OH})_{2}\right\}$ a $10 \%$, o qual reage com o $\mathrm{CO}_{2}$ proveniente da atividade respiratória das sementes, resultando em carbonato de bário $\left(\mathrm{BaCO}_{3}\right)$. Os frascos foram interligados por uma mangueira de silicone acoplada a uma trompa aspiradora de ar.

O fluxo de ar foi regulado por uma torneira, permitindo o controle de sua velocidade por meio da observação de bolhas formadas nos frascos. As sementes dos diferentes lotes (dois gramas) foram acondicionadas em recipiente plástico por 60 minutos, imersas em água destilada, à temperatura de $25^{\circ} \mathrm{C}$. Após esse período, as sementes foram secadas e colocadas no aparelho, onde permaneceram por 60 minutos.

Após a permanência no aparelho, foram coletadas três alíquotas de $10 \mathrm{~mL}$ da solução de $\mathrm{BaCO}_{3}$ em Erlenmeyer, adicionou-se duas gotas de fenolftaleína e realizou-se a titulação com ácido clorídrico $(\mathrm{HCl}) 0,1 \mathrm{~N}$ em bureta de $50 \mathrm{~mL}$, de cada alíquota. No ponto de viragem foi registrado o volume de $\mathrm{HCl}$ gasto em cada alíquota, o qual está diretamente relacionado com a quantidade de $\mathrm{CO}_{2}$ fixado pela solução de $\mathrm{Ba}(\mathrm{OH})_{2}$ e foi utilizado no cálculo da atividade respiratória das sementes, sendo o $\mathrm{CO}_{2}$ fixado proveniente do processo de respiração (Mendes et al., 2009). O cálculo da atividade respiratória foi realizado com base na seguinte equação: $\mathrm{N} \mathrm{x}$ D x 22 (Müller, 1964), em que: $\mathrm{N}=$

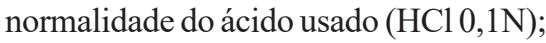
$\mathrm{D}=$ diferença entre o volume de $\mathrm{HCl}$ gasto na titulação da prova em branco e o volume de $\mathrm{HCl}$ gasto na titulação da amostra; $22=$ normalidade do $\mathrm{CO}_{2}$. $\mathrm{O}$ resultado foi expresso em quantidade de dióxido de carbono liberado por grama de semente, por hora $(\mu \mathrm{g} \mathrm{CO} / \mathrm{g}$ semente/h).

Os dados obtidos foram submetidos à análise de variância e as médias comparadas pelo teste de Tukey a 5\% de probabilidade através do programa SISVAR (Sistema para Análise de Va- 
Tabela 1. Germinação (G), primeira contagem de germinação (PC), emergência de plântulas (E), índice de velocidade de emergência de plântulas (IVE), lixiviação de potássio (LK) e atividade respiratória (AR) de lotes de sementes de rúcula (Eruca sativa), cultivares Cultivada e Folha Larga \{germination (G), first count (PC), seedling emergence (E), seedling emergence rate index (IVE), leaching of potassium (LK) and respiratory activity (AR) of seed lots of rocket (Eruca sativa), cultivars Cultivada and Folha Larga\}. Mossoró, UFERSA, 2013.

\begin{tabular}{|c|c|c|c|c|c|c|c|}
\hline Cultivar & Lote & $\begin{array}{c}G \\
(\%)\end{array}$ & $\begin{array}{l}\mathrm{PC} \\
(\%) \\
\end{array}$ & $\begin{array}{l}E \\
(\%) \\
\end{array}$ & $\begin{array}{r}\text { IVE } \\
(\%) \\
\end{array}$ & $\begin{array}{c}\text { LK } \\
(\mathrm{ppm})\end{array}$ & $\begin{array}{c}\mathrm{AR} \\
(\mu \mathrm{g} \mathrm{CO} / \mathrm{g} \text { semente/h) } \\
\end{array}$ \\
\hline \multirow{5}{*}{ Cultivada } & 1 & $91 \mathrm{ab}$ & $89 a^{*}$ & $90 \mathrm{a}$ & $21,33 a$ & $25,93 a$ & $2,58 \mathrm{a}$ \\
\hline & 2 & $93 a b$ & $90 \mathrm{a}$ & $86 a$ & $18,77 \mathrm{ab}$ & $26,87 \mathrm{a}$ & $2,66 \mathrm{a}$ \\
\hline & 3 & $95 a$ & $93 a$ & $88 \mathrm{a}$ & $15,83 b$ & $27,50 \mathrm{a}$ & $2,18 \mathrm{ab}$ \\
\hline & 4 & $84 b$ & $81 \mathrm{a}$ & $71 b$ & $15,75 b$ & $43,33 c$ & $1,23 b c$ \\
\hline & 5 & $71 \mathrm{c}$ & $58 \mathrm{~b}$ & $68 \mathrm{~b}$ & $9,97 \mathrm{c}$ & $34,16 \mathrm{~b}$ & $0,80 \mathrm{c}$ \\
\hline \multirow[t]{3}{*}{ CV (\%) } & & 5,9 & 7,0 & 8,2 & 10,7 & 4,9 & 29,1 \\
\hline & 6 & $94 a$ & $89 a$ & $88 \mathrm{a}$ & $14,43 a$ & $24,66^{\mathrm{a}}$ & $3,12 \mathrm{a}$ \\
\hline & 7 & $92 a$ & $84 a$ & $87 a$ & $14,04 \mathrm{a}$ & $34,57 \mathrm{bc}$ & $2,77 \mathrm{a}$ \\
\hline \multirow[t]{3}{*}{ Folha Larga } & 8 & $94 a$ & $92 \mathrm{a}$ & $84 a$ & $14,75 \mathrm{a}$ & $30,37 b$ & $2,36 \mathrm{ab}$ \\
\hline & 9 & $90 \mathrm{a}$ & $84 a$ & $78 \mathrm{a}$ & $12,74 \mathrm{a}$ & $32,20 \mathrm{bc}$ & $1,87 b c$ \\
\hline & 10 & $67 \mathrm{~b}$ & $55 \mathrm{~b}$ & $60 \mathrm{~b}$ & $9,19 \mathrm{~b}$ & $36,82 \mathrm{c}$ & $1,33 \mathrm{c}$ \\
\hline CV (\%) & & 8,3 & 6,3 & 9,4 & 10,1 & 7,4 & 17,1 \\
\hline
\end{tabular}

*Médias seguidas de mesma letra, na coluna, não diferem entre si pelo teste Tukey, $\mathrm{p}<0,05$ (means followed by the same letter in the column do not differ by Tukey $\mathrm{p}<0.05)$.

riância) (Ferreira, 2011). Foram realizadas análises de correlação de Pearson, a 1 e $5 \%$ de probabilidade, entre os dados obtidos nos testes de germinação e vigor com a atividade respiratória.

\section{RESULTADOS E DISCUSSÃO}

Os teores de água das sementes das duas cultivares (Cultivada e Folha Larga) foram semelhantes, com $7,2 \pm 0,5 \%$ e $7,6 \pm 0,5 \%$, respectivamente. Esta pequena variação indica que não houve interferência do teor de água das sementes nos resultados obtidos nos testes de vigor. Isso é importante para a execução dos testes, uma vez que a uniformização do teor de água das sementes dos diferentes lotes é fundamental para a padronização das avaliações e obtenção de resultados consistentes (Kikuti \& Marcos-Filho, 2012). Nesse sentido, Marcos-Filho (2015) enfatizou a importância da uniformização do grau de umidade das sementes, uma vez que a variação da umidade das sementes pode afetar os resultados dos testes.

Tabela 2. Coeficientes de correlação de Pearson entre a atividade respiratória e os testes de germinação $(\mathrm{G})$, primeira contagem de germinação $(\mathrm{PC})$, emergência de plântulas (E), índice de velocidade de emergência de plântulas (IVE) e lixiviação de potássio (LK) de lotes de sementes de rúcula (Eruca sativa), cultivares Cultivada e Folha Larga \{Pearson correlation coefficients between respiratory activity and germination $(\mathrm{G})$, first count (PC), seedling emergence (E), seedling emergence rate index (IVE) and leaching of potassium (LK) of seed lots of rocket (Eruca sativa) cultivars Cultivada and Folha Larga\}. Mossoró, UFERSA, 2013.

\begin{tabular}{lcc}
\hline Testes & \multicolumn{2}{c}{ Correlação de Pearson } \\
\cline { 2 - 3 } & Cultivada & Folha Larga \\
\hline G & $0,823^{*}$ & $0,864^{*}$ \\
PC & $0,878^{*}$ & $0,896^{*}$ \\
E & $0,954^{* *}$ & $0,958^{* *}$ \\
IVE & $0,889^{*}$ & $0,885^{*}$ \\
LK & $-0,937^{*}$ & $-0,873^{*}$ \\
\hline
\end{tabular}

*e**significativa a 5 e $1 \%$ de probabilidade $\left(*\right.$ and ${ }^{* *}$ significant at $\mathrm{p}<0.05$ and $\mathrm{p}<0.01$, respectively).

Observou-se diferença estatística entre os lotes das cultivares Cultivada e Folha Larga através dos testes de germinação, primeira contagem de germinação, emergência de plântulas em campo, índice de velocidade de emergência, lixiviação de potássio e atividade respiratória (Tabela 1 ).

Para os lotes de 'Cultivada', verificou-se pelo teste de germinação, assim como de primeira contagem de germinação, porcentagem e índice de velocidade de emergência de plântulas que o lote 5 apresentou resultados inferiores quando comparado aos demais lotes (Tabela 1). No tocante aos lotes de 'Folha Larga' e considerando-se esses parâmetros, o lote 10 apresentou menor qualidade fisiológica, diferindo dos lotes $6,7,8$ e 9 , que foram agrupados em nível superior. Em trabalho realizado com sementes de rúcula, utilizando estes testes, houve eficiência para agrupar diferentes lotes de sementes desta hortaliça em diferentes níveis de qualidade (Alves \& Sá, 2010). Estas diferenças de qualidade fisiológica dos lotes, também, foram confirmadas pelos resultados dos testes de primeira contagem de germinação, porcentagem e velocidade de emergência de plântulas (Tabela 1).

Para os lotes de 'Cultivada', o teste 
de lixiviação de potássio, apontou os lotes 1,2 e 3 como os de maior vigor, enquanto os lotes 4 e 5 de vigor inferior. No que diz respeito à cultivar Folha Larga, esse teste indicou o lote 6 como o mais vigoroso e o lote 10 como o de menor vigor (Tabela 1). Essa inferioridade também foi detectada nos testes de germinação e emergência de plântulas. O teste de lixiviação de potássio permite obter informações sobre a qualidade fisiológica de lotes de sementes com maior rapidez e agilidade; essa afirmação é comprovada pelos resultados obtidos por Alves \& Sá (2010) e Steiner et al. (2011), trabalhando, respectivamente, com sementes de rúcula e triticale ( $X$. triticosecale), obtiveram resultados semelhantes aos encontrados no presente trabalho, verificando que lotes de maior qualidade fisiológica apresentam menor lixiviação de potássio.

Como nos demais testes realizados, os lotes com menor atividade respiratória foram o 5 (cv. Cultivada) e 10 (cv. Folha Larga). Resultados semelhantes foram encontrados por Aumonde et al. (2012) e Mendes et al. (2009) que, trabalhando com sementes de feijão-miúdo e soja, respectivamente, observaram que os lotes com maior vigor apresentaram maior atividade respiratória e os de menor vigor, baixa respiração.

Para a cultivar Folha Larga foi possível classificar, através do teste de respiração, o lote 9 como sendo de qualidade fisiológica intermediária, não diferindo estaticamente do lote 10 (de menor vigor), o que não foi possível verificar nos testes de germinação, e emergência de plântulas (porcentagem e velocidade). Segundo Pereira (2012), as alterações responsáveis pela queda de vigor ocorrem paralelamente à redução da taxa respiratória das sementes. A recuperação estrutural das sementes ocorre à medida que a hidratação prossegue e os mitocôndrios se tornam mais eficientes na fosforilação oxidativa. $\mathrm{O}$ desempenho do lote pode ser visualizado como consequência do período necessário para que os mitocôndrios fiquem mais eficientes, passem a executar funções respiratórias e o sistema de membranas se torne melhor organizado
(Marcos-Filho, 2015).

A atividade e integridade dos mitocôndrios de embriões viáveis aumentam a partir do início da embebição, o que torna mais eficiente a produção de ATP, refletindo em elevação do consumo do oxigênio e consequentemente elevação da produção de gás carbônico (Bewley \& Black, 1994). Dessa forma, o lote mais vigoroso tende a respirar mais que um lote com menor vigor, em um mesmo período de tempo.

Pode-se observar, na Tabela 2, que houve correlação significativa entre a atividade respiratória e as demais variáveis, para as cultivares Cultivada e Folha Larga. Nesse sentido, a redução da atividade respiratória das sementes está relacionada a menores valores de germinação, porcentagem e velocidade de emergência de plântulas e aumento da lixiviação de potássio.

Dessa forma, pode-se concluir que o método de Pettenkofer é eficiente na determinação da atividade respiratória de sementes de rúcula, cv. Cultivada e Folha Larga, podendo ser empregado para avaliar o vigor.

\section{REFERÊNCIAS}

ALVES, CZ; SÁ, ME. 2009. Condutividade elétrica em sementes de rúcula. Revista Brasileira de Sementes 31: 203-215.

ALVES, CZ; SÁ, ME. 2010. Avaliação do vigor de sementes de rúcula pelo teste de lixiviação de potássio. Revista Brasileira de Sementes 32: 108-116.

AUMONDE, TZ; MARINI, P; MORAES, DM; MAIA, MS; PEDÓ, T; TILLMANN, MAA; VILLELA, FA. 2012. Classificação do vigor de sementes de feijão-miúdo pela atividade respiratória. Interciência 37: 55-58.

BEWLEY, JD; BLACK, M. 1994. Seeds: physiology of development and germination. New York: Plenum Press. 445p.

BRASIL. 2009. Ministério da Agricultura, Pecuária e Abastecimento. Regras para análise de sementes. Ministério da Agricultura, Pecuária e Abastecimento. Secretaria de Defesa Agropecuária. Brasília: Mapa/ACS. 395p.

COIMBRA, RA; MARTINS, CC; TOMAZ, CA; NAKAGAWA, J. 2009. Testes de vigor utilizados na avaliação da qualidade fisiológica de lotes de sementes de milho-doce. Ciência Rural 39: 2402-2408.

DODE, JS; MENEGHELLO, GE; MORAES,
DM; PESKE, ST. 2012. Teste de respiração para avaliar a qualidade fisiológica de sementes de girassol. Revista Brasileira de Sementes 34: 686-691.

DODE, JS; MENEGHELLO, GE; TIMM, FC. MORAES, DM; PESKE, ST. 2013. Teste de respiração em sementes de soja para avaliação da qualidade fisiológica. Ciência Rural 43: 193-198.

FERREIRA, DF. 2011. Sisvar: a computer statistical analysis system. Ciência e Agrotecnologia 35: 1039-1042.

ISTA - International Seed Testing Association. 2012. Handbook of vigour test methods. 3.ed. Zurich: ISTA. $117 \mathrm{p}$.

KIKUTI, ALP; MARCOS-FILHO, J. 2012. Testes de vigor em sementes de alface. Horticultura Brasileira 30: 44-50.

MAGUIRE, JD. 1962. Speed of germinationaid in selection and evaluation for seedling emergence and vigour. Crop Science 2: 176-177.

MARCOS-FILHO, J. 2015. Fisiologia de sementes de plantas cultivadas. 2. ed., Londrina: ABRATES, 660p.

MENDES, CR; MORAES, DM; LIMA, MGS; LOPES, NF. 2009. Respiratory activity for the differentiation of vigor on soybean seeds lots. Revista Brasileira de Sementes 31: 171-176.

MÜLLER, LE. 1964. Manual de laboratório de fisiologia vegetal. Costa Rica: Instituto Interamericano de Ciências Agrícolas de la OEA. 165p.

OLIVEIRA, LM; CAVALHEIRO, VBD; MORAES, DM; TILMANN, MAA; SCHUCH, LOB. 2015. Medição do $\mathrm{CO}_{2}$, como método alternativo para a diferenciação do vigor de lotes de sementes de melancia. Ciência Rural 45: 606-611.

PÊGO, RG; NUNES, UR; MASSAD, MD. 2011. Qualidade fisiológica de sementes e desempenho de plantas de rúcula no campo. Ciência Rural 41: 341-1346.

PEREIRA, EM. 2012. Avaliação da qualidade fisiológica de sementes de pimenta e pimentão por meio da atividade respiratória. Lavras: UFLA. 69p (Dissertação mestrado).

PIÑA-RODRIGUES, FCM; FIGLIOLIA, MB; PEIXOTO, MC. 2004. Testes de qualidade. In FERREIRA, AG; BORGHETI F (eds). Germinação: do básico ao aplicado. Porto Alegre: Artmed. p.283-297.

SILVA, LJB; CAVALCANTE, ASS; ARAÚJO NETO, SE. 2009. Produção de mudas de rúcula em bandejas com substratos à base de resíduos orgânicos. Ciência e Agrotecnologia 33: 1301-1306.

STEINER, F; OLIVEIRA, SSC; MARTINS, CC; CRUZI, SJS. 2011. Comparação entre métodos para a avaliação do vigor de lotes de sementes de triticale. Ciência Rural 41: 200-205.

TRANI, PE; PASSOS, FA. 1998. Rúcula (pinchão). In: FAHL, JI; CAMARGO, MBP; PIZINATTO, MA; BETTI, JA; MELO, AMT; DEMARIA, IC; FURLANI, AMC (eds). Instruções agrícolas para as principais culturas econômicas. Campinas: IAC. p. 241242 (Boletim, 200). 